\title{
Assessing interactions between crop biophysical parameters and X-band backscattering using empirical data and model sensitivity analysis
}

\author{
Giacomo Fontanelli ${ }^{1, \mathrm{a}}$, Francesco Montomoli ${ }^{2}$, Ramin Azar ${ }^{1, \mathrm{~b}}$, Giovanni Macelloni ${ }^{2}$, Paolo Villa ${ }^{1, *}$ \\ ${ }^{1}$ Institute for Electromagnetic Sensing of the Environment (IREA), CNR, Milan, Italy \\ ${ }^{2}$ Institute for Applied Physics (IFAC), CNR, Florence, Italy \\ ${ }^{a}$ Present affiliation: Institute for Applied Physics (IFAC), CNR, Florence, Italy \\ ${ }^{b}$ Present affiliation: Planetary Remote Sensing Inc., Coquitlam, Canada \\ * corresponding author: villa.p@irea.cnr.it (email)
}

Abstract - Active microwave remote sensing data at different frequencies can provide crucial information on crop morphology and conditions, thus effectively supporting agronomic management at different scales. Despite the ever-increasing availability of spaceborne platforms and the extensive research developed throughout more than two decades, some knowledge gaps still await to be filled towards operational use, dealing with SAR backscatter response to crop-specific features and seasonal dynamics, including the effects of agronomic practices. In this work, we used variance-based global sensitivity analysis (GSA) as a quantitative framework for investigating the sensitivity of $\mathrm{X}$-band backscattering to agronomic and morphological features typical of two different crops, maize and rice. To this end, we jointly exploited empirical data on crop status and growth, high-resolution TerraSAR-X data, and microwave radiative transfer model (RTM) simulations. Phenologyinformed simulations allowed us to quantify the contributions of different scattering mechanisms for the two crops under varying observation setups, to assess the sensitivity of $X$-band backscattering to morpho-structural crop biophysical parameters (and their interactions), and to evaluate the effects of crop biomass on backscatter across growth stages. In particular, multidimensional GSA outputs accounting for model input correlations through Shapley effects provided a comprehensive suite of information on the relative proportion of total backscatter variance explained by a range of parameters and a quantitative description of the different behavior in vertical and horizontal polarization (changing throughout plant growth) in paddy rice, and the mixed contribution of canopy density and leaf angle distribution (depending on the incident angle) in maize.

Index Terms - Crop biophysical parameters, global sensitivity analysis (GSA), radiative transfer model (RTM), TerraSAR-X, maize, rice

(C) 2021 IEEE. Personal use of this material is permitted. Permission from IEEE must be obtained for all other uses, in any current or future media, including reprinting/republishing this material for advertising or promotional purposes, creating new collective works, for resale or redistribution to servers or lists, or reuse of any copyrighted component of this work in other works. 


\section{INTRODUCTION}

Timely information about agricultural crops properties (e.g. typology, phenology, productivity, health) is crucial for proper agronomic planning and management by farmers and public administrations [1]-[2].

Active microwave data at different frequencies acquired by spaceborne SAR systems have been extensively tested and employed in developing remote sensing based methods for mapping crop types, retrieving biophysical parameters, and monitoring agronomic cycles, e.g. for the estimation of biomass and growth status, targeting major cereal crops, e.g. [3]-[8]. The new generation of satellite platforms (e.g. TerraSAR-X, COSMO-SkyMed, Sentinel-1) provides enhanced quality and availability in time and space of SAR data encouraging their use for operational crop monitoring, e.g. [9]-[11]. Within this frame, the determination of the scattering contributions of soil and vegetation and their seasonal variations are fundamental for understanding the SAR signatures and derive information on plant health and growing conditions [12]-[14].

Although the path traveled so far has been long and largely fruitful, the recent review by Steele-Dunne et al. [14] identifies persisting knowledge gaps, dealing with: capturing the crop backscattering dynamics throughout the growing season, disentangling the effects of different canopy-soil system components, and fully taking into account cropspecific features. In particular, the effects of all from these factors on crop backscatter need to be assessed in a quantitative fashion [15].

A statistical framework for evaluating the relations of different crop parameters and SAR observation characteristics can be provided by variance-based global sensitivity analysis (GSA), which has been recently applied to tackled specific problems and remote sensing applications in different spectral domains: from optical range [16]-[19] to microwaves [20]-[22].

In this paper, GSA was used to investigate the sensitivity of microwave backscattering at X-band to agronomic and morphological features typical of two of the most globally relevant crops, maize and rice, which together account for around $65 \%$ of global cereal production [23]. To this end, we jointly used data on crop status and growth collected in the fields, high-resolution multi-temporal spaceborne backscattering data acquired from TerraSAR-X, and microwave radiative transfer model (RTM) simulations, to assess the evolution of biophysical parameters for both crops (including plant biomass) during their growth and to analyze the contribution of different components of the vegetation-soil system to total backscattering.

The main target of this paper is to provide a better interpretation of X-band SAR data over rice and maize, taking into account their biophysical properties. To meet this target, the objectives are: i) to refine the implementation of a single layer RTM of X-band crop backscatter by including second order interactions between canopy elements into model formulation; ii) to run model simulations to quantify the main X-band scattering mechanisms, under different polarizations and observation setups of the different canopy components for rice and maize, based on a solid empirical database of crop biophysical parameters, and iii) to assess the sensitivity of X-band backscattering to morpho-structural crop biophysical parameters and their interactions. 


\section{STUDY AREA AND DATASET}

The test site is located in Northern Italy, at the south-westerly portion of the Lombardy region, next to the Sesia river, in the Rosasco municipality $\left(45.25^{\circ} \mathrm{N}, 8.58^{\circ} \mathrm{E}\right)$ as shown in Fig. 1. Here, almost $2000 \mathrm{~km}^{2}$ are dedicated to rice cropping, providing the $92 \%$ of the entire Italian rice production. Besides rice, either maize and soybean are cropped in the area, especially on terrains less suitable to rice cultivation, such as sandy soils. The area is flat, with a uniform countryside interspersed with a network of artificial canals delimiting the fields. The climate is continental, with significant daily and annual temperature variations; average annual precipitation is between 750 and $800 \mathrm{~mm}$, distributed over 70-90 days.

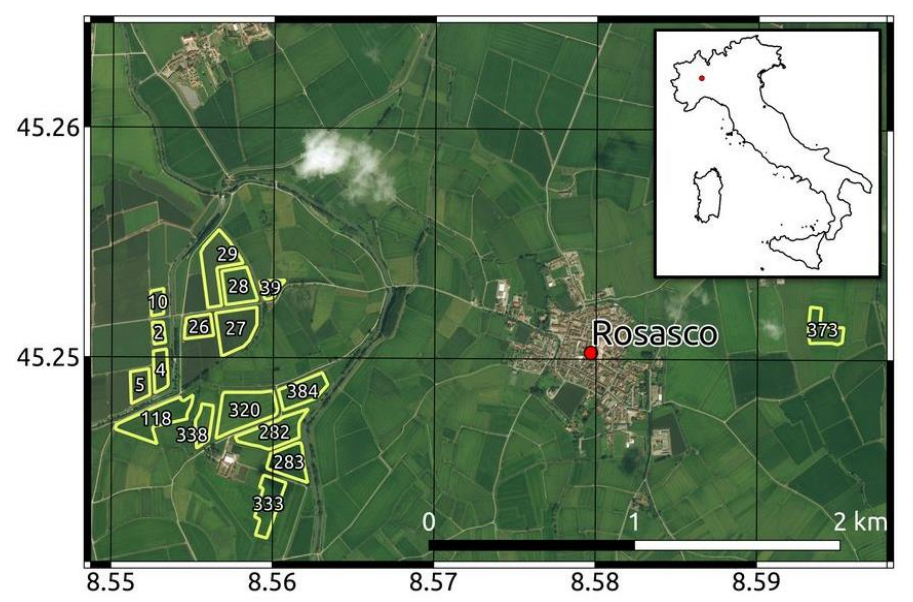

Fig. 1. Location of the study area and of the crop fields interested by the in situ campaigns (yellow polygons).

\section{A. Crop parameters}

A total of 14 field campaigns have been carried out in spring and summer of 2014, 2015 and 2016 years, in order to cover the entire vegetative seasons of two summer crop types: maize and rice. A total of 25 plots have been investigated, with extension ranging from 1 to 4.5 ha: 14 plots for rice and 11 for maize.

During fieldwork, observations and measurements were collected for biophysical and agronomic parameters related to: i) agronomic practices (crop species and cultivar, sowing date, sowing scheme and density), ii) substrate (soil moisture, flooding conditions), iii) crop phenology (described using BBCH scale [24] and detail photos), iv) plant morphology (plant height, number of leaves, leaf size, stem size), and v) biomass and density (biomass, plant water content, plant area index - PAI, average leaf angle - ALA). The complete database of crop parameters collected and measured is available at PANGAEA [25], and a synthetic overview of the main characteristics of sampled field are provided in Supplementary Fig. S1 and Supplementary Table S1.

\section{B. TerraSAR-X data}

Simultaneously to some in situ data, 14 SAR satellite scenes were acquired from the DLR - TerraSAR-X (TSX) sensor (Stripmap dual-pol scenes, local incidence angle $\theta=40^{\circ}$; Orbit 116, beam 012) on the study area, including 9 at $\mathrm{HH}$ and $\mathrm{HV}$ polarizations (acquired in 2014 and 2015) and 5 at VV and $\mathrm{HH}$ polarizations (in 2016). 


\section{METHODS}

\section{A. SAR data processing}

TSX data acquired at $\mathrm{HH}, \mathrm{VV}$, and $\mathrm{HV}$ polarizations were radiometrically calibrated following [26], including multilooking (7R x 4A) and terrain correction (using SRTM DTM), to obtain sigma nought $\left(\sigma^{\circ}\right)$ maps in different polarizations and with $10 \mathrm{~m}$ spatial resolution over our study area. X-band $\sigma^{\circ}$ of maize and rice fields monitored was extracted from TSX data for three seasons (14 dates), as mean value of $10 \mathrm{~m}$ pixels falling within the fields' boundary. The seasonal evolutions of TSX backscatter for monitored fields are shown in Supplementary Fig. S2.

\section{B. X-band crops backscattering modelling}

A single-layer microwave radiative transfer model (RTM) based on the works developed by Karam et al. [12] was used to simulate the seasonal evolution of X-band $\sigma^{\circ}$ from maize and rice fields and to evaluate the contribution of different components of the vegetation-soil system. The capabilities of RTM to simulate at X-band the seasonal growth of two distinct categories of crops, namely narrow-leaved and broad-leaved crops, have been already considered in literature [6],[27]. More recently, Liao et al. [28] investigated the effect of multiple scattering in the RTM simulations of corn fields from C- to Ku-band. The main outcome was that, when optical thickness and scattering albedo are $>0.4$, single scattering contribution is not sufficient to simulate RTM backscattering, while multiple scattering contributes significantly at both $\mathrm{VV}$ and $\mathrm{HH}$ polarization. It was also mentioned that the first and second orders together contribute at $90 \%$ of the total, while higher orders effect are minor. Starting from these considerations, a second order RTM has been implemented [12].

Vegetation canopy was modelled as a homogeneous layer of randomly distributed scatterers, composed by lossy dielectric cylinders (stems) and elliptical disks of fixed width (leaves). The backscattering model of each element follow the infinite cylinder approximation, and the Generalized Rayleigh-Gans (G RG) approximation as described in Karam and Fung [29]-[30]. Dielectric constant of both stems and leaves was obtained from the volumetric moisture through the dual dispersion model by Ulaby and El-Rayes [31]. Stems were modelled as near vertical cylinders (varying in a range of +/- 10 degrees) and leaves angular distribution derived from in situ measured ALA. The backscattering contribution from bare soil was based on Oh model [32], using the roughness and soil moisture contents measured in the field campaigns. For simulating canopy background of rice in typically flooded terrain conditions, we assumed flat water surface condition whose reflectivity can be simple simulated trough the Fresnel's model. Maize and rice fruits (ears) were not modelled because the computational burden for their inclusion was not counterbalanced by a guarantee of increased accuracy, due to the low relevance of ears scattering contribution in maize at X-band on one hand and to the lack of consistently reliable simulation solutions for rice ears [33] on the other. This practically imply that simulations developed in this work are morphologically representative of crops before they reach fruit ripening phase - i.e. covering the growing cycle up to $\mathrm{BBCH}<80$ for maize plants and to $\mathrm{BBCH}<60$ for rice plants.

The seasonal change of radar backscattering from maize and rice fields has been simulated along the three years of campaigns (from 2014 to 2016) using in situ data acquired on the field as inputs for the model and the RTM performance was assessed in comparison to $\mathrm{TSX} \sigma^{\circ}$ by computing average bias and root mean square error (RMSE). For this comparison, only crop fields in non-drying conditions (volumetric plant water content > 0.3) were considered, 
while modelled $\sigma^{\circ}$ lower than $-25 \mathrm{~dB}$ was excluded, since it falls below the expected noise equivalent $\sigma^{\circ}$ (NESZ) for TSX for TSX dual-pol Stripmap products with configuration used (ranging from -23 to $-24 \mathrm{~dB}$ ).

\section{Simulation of seasonal evolution of crop biophysical parameters}

To quantitatively assess the sensitivity of X-band backscatter to crop biophysical parameters, i.e. RTM inputs, as well as to evaluate the influence of different scattering mechanisms to the total $\sigma^{\circ}$, an in silico experiment was designed basing on model simulations of agronomically consistent crop conditions. These conditions are representative of machine-seeded rice and maize grown in temperate Europe, as observed and measured from empirical data collected in our study area. Towards this, a first plant height partition into 10 bins of equal width, i.e. $0.1 \mathrm{~m}$ wide bins for rice and $0.4 \mathrm{~m}$ wide bins for maize, were done. For each bin $j=(1, \ldots, 10)$, the mean and standard deviation of eight target crop biophysical parameters (BPs) measured over our study fields, including: plant height ( $\mathrm{P}_{\text {height}}$; which in our singlelayer RTM is the same as stem length), stem radius $\left(\mathrm{S}_{\mathrm{rad}}\right)$, plant water content $\left(\mathrm{P}_{\mathrm{mv}}\right)$, plant density $\left(\mathrm{P}_{\text {dens }}\right)$, number of leaves per plant $\left(\mathrm{N}_{\text {leaves }}\right)$, average leaf angle (ALA), leaf half-length ( $\left.\mathrm{a} 1_{\text {leaves }}\right)$, leaf half-width ( $\left.\mathrm{a} 2_{\text {leaves }}\right)$ were computed. Then, the relations of different BPs with plant height, taken as the key dynamic descriptor of phenological evolution through the growing season were examined, expressing them into simple stochastic models in the form of:

$$
B P_{i}=f\left(P_{\text {height }}\right)+\varepsilon_{i j}
$$

where $i=(1, \ldots, 7)$ is indexing seven BPs expressed as a function of plant height; $f()$ is the empirical (deterministic) model calibrated using in situ measured crop data (see Supplementary Fig. S3-S4) and $\varepsilon_{i j} \sim \mathcal{N}\left(0, \sigma_{i j}\right)$ is the stochastic term varying with each $\mathrm{BP}_{i}$.

For each bin $j, 300$ realizations of each $\mathrm{BP}_{i}$ were computed from (1) fed with plant height values randomly generated from uniform distribution (bounded by min-max of each individual bin), finally amounting to a comprehensive database $(\mathrm{N}=3000)$ of realistic combinations of maize and rice biophysical parameters, following the evolution of crop growth, to be set as input for RTM simulations (parameters description and ranges are shown in Supplementary Table S2).

From this database, estimates of standing plant biomass were derived applying an allometric model (Supplementary Fig. S5) fed with all simulated combinations of BPs separately for maize and rice $(\mathrm{N}=3000)$.

\section{Sensitivity analysis}

A sensitivity analysis was carried out using variance-based global sensitivity metrics to quantify the interactions between X-band backscattering and crop biophysical parameters (plant morpho-structural features and water content) described by RTM inputs.

Variance-based sensitivity analysis, designed to assess how uncertainty of different model inputs influences uncertainty in model output(s) or, in other words, how different inputs contribute to the variance of model output(s) over the range of input parameters [34]. This test is commonly implemented based on the seminal work of Sobol' [35], computing the so called Sobol' indices. However, Sobol' indices are difficult to both estimate and interpret when input parameters are not independent, since they feature a correlation structure [36]-[37]. For overcoming the issue of co- 
variance decomposition in case of correlated inputs, the Shapley effects have been recently proposed by some authors [37]-[38], as a normalized version of the Shapley value, originally introduced in game theory for optimizing the distribution of values (gains and costs) to different actors working in a coalition [39]. In the framework of sensitivity analysis, input parameters can be seen as the actors and the value attached to each subset of inputs (i.e. coalition of actors) as the explanatory power of this subset, so that the Shapley effects can be interpreted as relative importance of each model input in determining the output(s).

Starting from a model $Y=f(\boldsymbol{X})$, featuring $d$ scalar inputs $\boldsymbol{X}=\left(X_{1}, \ldots, X_{d}\right)^{\mathrm{T}}$ and one scalar output $Y$, the closed Sobol' indices associated to a subset of inputs designated by $u$, where $u \subseteq\{1, \ldots, d\}$, are computed as:

$$
S_{u}^{c l o}=\frac{\operatorname{Var}\left(\mathbb{E}\left[Y \mid X_{u}\right]\right)}{\operatorname{Var}(Y)}
$$

The Shapley effects are then derived as combinations of the closed Sobol' indices, according to the formula:

$$
S h_{i}=\frac{1}{d} \sum_{u \subseteq-\{i\}}\left(\begin{array}{c}
d-1 \\
|u|
\end{array}\right)^{-1}\left(S_{(u \cup\{i\})}^{c l o}-S_{u}^{c l o}\right)
$$

where $-\{i\}$ is the set of input parameters $\{1, \ldots, d\}$ not containing $i$, and $|u|$ is the cardinality of $u$.

The Shapely effects are positive quantities, sum up to unity, and distribute interaction effects among correlated variables equitably to each input involved in the interaction, thus being easily interpreted as relative variable importance metrics even in case of dependent, correlated inputs [37].

In our case, crop BPs combinations generated in silico as described in section IIIC were used as input for RTM for calculating total $\mathrm{X}$-band $\sigma^{\circ}$ as well as its components (from: leaves, stems, leaves-stems interaction, soil, soil-canopy interaction) in four polarizations ( $\mathrm{VV}, \mathrm{HH}, \mathrm{VH}, \mathrm{HV})$ and under four incidence angles $\theta\left(20^{\circ}, 30^{\circ}, 40^{\circ}, 50^{\circ}\right)$. As this, a total of $\mathrm{N}=12000$ RTM simulations $(\mathrm{N}=3000$ for each $\theta$ ) for each crop (maize or rice) constituted the basis for calculation of Shapley effects of nine parameters, including $\theta$ and eight target BPs $\left(\mathrm{P}_{\text {height }}, \mathrm{S}_{\mathrm{rad}}, \mathrm{P}_{\mathrm{mv}}, \mathrm{P}_{\text {dens }}, \mathrm{N}_{\text {leaves }}, A L A\right.$, $\left.\mathrm{a} 1_{\text {leaves }}, \mathrm{a} 2_{\text {leaves }}\right)$.

The direction of relations between crop biophysical parameters and X-band backscattering was assessed over the same dataset using Partial Rank Correlation Coefficients (PRCC) [36]. As PRCC are based on monotonic assumptions, they were separately computed for subsets of RTM simulations maintaining monotonicity of output across the input range; this was done by dividing the simulations into two groups based on plant height. For rice, the two groups correspond to plants lower than $40 \mathrm{~cm}$, before stem elongation phase starts $\left(\mathrm{BBCH}<30\right.$, biomass $\left.<0.4 \mathrm{~kg} \mathrm{~m}^{-2}\right)$, and plants higher than $40 \mathrm{~cm}$, starting from stem elongation phase $\left(\mathrm{BBCH} \geq 30\right.$, biomass $\left.\geq 0.4 \mathrm{~kg} \mathrm{~m}^{-2}\right)$. For maize, the two groups correspond to plants lower than $150 \mathrm{~cm}$, i.e. up to halfway stem elongation $\left(\mathrm{BBCH}<35\right.$, biomass $<1.0 \mathrm{~kg} \mathrm{~m}^{-}$ ${ }^{2}$ ), and plants higher than $150 \mathrm{~cm}$, i.e. from late stem elongation phase and heading $(\mathrm{BBCH} \geq 35$, biomass $<1.0 \mathrm{~kg} \mathrm{~m}$ ${ }^{2}$ ). Shapley effects and PRCC were computed with package sensitivity v 1.16.2, built under R v.4.0.2 [40]. 


\section{RESULTS AND DISCUSSION}

\section{A. X-band crop backscattering modelling performance}

The minimum $\sigma^{\circ}$ from TSX data over our study fields during the three years of data collection is retrieved over flooded rice paddies, scoring $-21.7 \mathrm{~dB}$ in co-pol $(\mathrm{HH})$ and $-23.2 \mathrm{~dB}$ in cross-pol (HV), which are slightly higher than theoretical NESZ for TSX products we used (around -24 dB). Fig. 2a shows the relationship between maize $\sigma^{\circ}$ derived from TSX and RTM outputs, at both HH and VV polarizations. It emerges that the model and data are in good agreement showing low Bias and RMSE (Bias $<1.0 \mathrm{~dB}$, RMSE $<1.7 \mathrm{~dB}$ ); in cross-pol HV, the matching is slightly worse $($ Bias $=-1.4 \mathrm{~dB}, \mathrm{RMSE}=2.3 \mathrm{~dB})$. The inclusion of second order terms accounting for interactions between canopy elements enhanced the matching with TSX measured $\sigma^{\circ}$ (Fig. 2) compared to RTM outputs considering only first order interactions (Supplementary Fig. S6), bringing to a consistent reduction in RMSE for co-pol $\sigma^{\circ}$ (by $0.2 \mathrm{~dB}$ and $0.8 \mathrm{~dB}$, respectively for $\mathrm{HH}$ and $\mathrm{VV}$ ). Improvements are even more marked in $\mathrm{HV}$ polarization, both in terms of RMSE reduction (by 2.2. $\mathrm{dB}$ ) and number of effective match-ups, i.e. where modelled $\sigma^{\circ}$ does not exceed $-25 \mathrm{~dB}$, increased from 14 to 33 .

For rice, the inclusion of second order interactions into RTM did not sensibly enhance the model performance in terms of matching TSX $\sigma^{\circ}$, with respect to RTM considering only first order terms. RTM simulations are generally aligned with TSX data, showing at HH polarization a Bias and a RMSE value of $0.4 \mathrm{~dB}$ and $3.1 \mathrm{~dB}$ respectively (Fig. 2b). These are in line with what obtained in previous works [41], while model performance at cross-pol is slightly worse $(\operatorname{RMSE}=3.9 \mathrm{~dB})$, with a systematic underestimation of $\sigma^{\circ} \mathrm{HV}$ by around $3 \mathrm{~dB}$. For VV pol, Fig. 2b panels highlight that the model we used tend to underestimate backscatter by around 60-70\%, when TSX $\sigma^{\circ}$ gets below -10 $\mathrm{dB}$. This underestimation is especially evident when $\sigma^{\circ}$ drops under $-15 \mathrm{~dB}$, such as in rice fields with plants higher than $0.5 \mathrm{~m}$ and very dense canopies (more than 400 plants per $\mathrm{m}^{2}$ ). Indeed, rice fields in our study area showed extremely high plant density at the beginning of the season (up to 516 plant $\mathrm{m}^{-2}$ ), reaching 1000-1500 individual stems

$\mathrm{m}^{-2}$ at peak of growth, far higher than densities registered in previous works, usually around 400-500 stems $\mathrm{m}^{-2}$ [13],[41], with a peak of 900 [22]. This means that commonly used RTM approaches might not be the best choice for simulating backscatter of very dense rice fields, and implies that the results of the sensitivity analysis we run over rice in VV pol need to be carefully weighted.

\section{B. Sensitivity of X-band backscatter to crop biophysical parameters and observation conditions}

Table 1 summarizes sensitivity of $\mathrm{X}$-band $\sigma^{\circ}$ to rice crop parameters and observation configuration, computed as Shapley effects and interpreted as relative proportion of total output variance explained by each model input. For rice, Sh scores highlight the primary role taken by the development of vertical, i.e. stems $\left(\mathrm{P}_{\text {height }}\right)$, and pseudo-vertical, i.e. narrow and erectophile leaves ( $\mathrm{a} 1_{\text {leaves }} / \mathrm{a} 2_{\text {leaves }}=28$ on average; measured ALA $=70 \pm 8^{\circ}$ ), canopy elements in dominating total $\sigma^{\circ}: \mathrm{P}_{\text {height }}$ and $\mathrm{a} 1_{\text {leaves }}$ together cover an amount of total variance varying from $42.1 \%$ to $47.8 \%$. The width of such vertical and pseudo-vertical elements $\left(S_{\text {rad }}, a 2_{\text {leaves }}\right)$ contribute a non-negligible part of remaining $\sigma^{\circ}$ variability, covering another $27.2-30.3 \%$ of variance. 

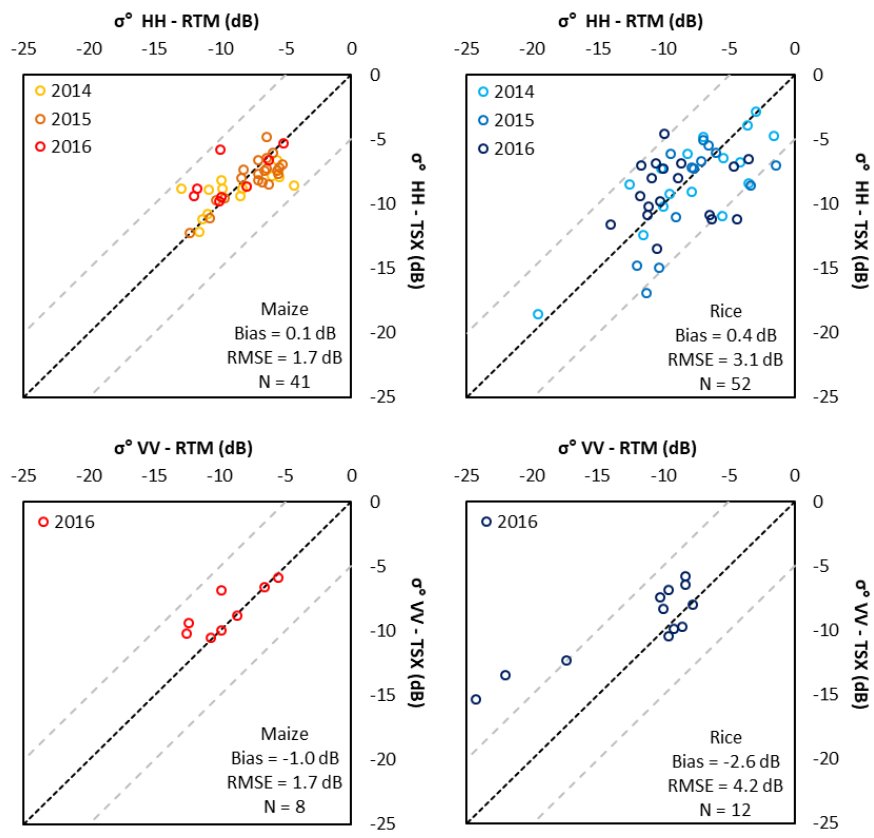

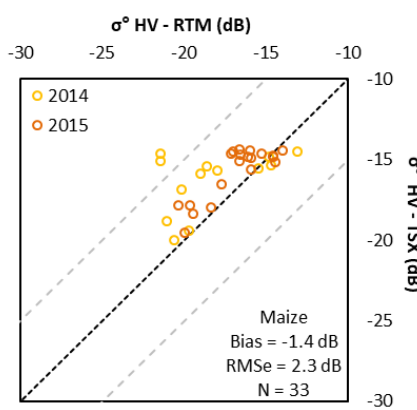

a)

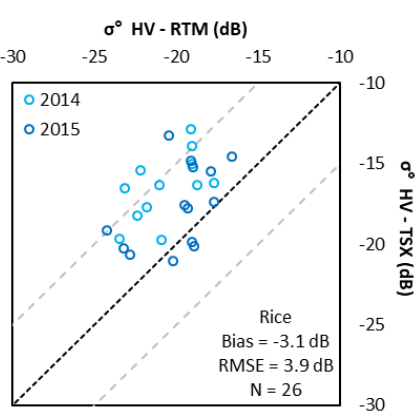

b)

Fig. 2. Scatter plots of X-band $\sigma^{\circ}$ simulated by RTM (including scattering contributions up to the second order) vs. extracted from TSX in three polarizations (VV, HH, HV) for monitored field: (a) maize and (b) rice.

Overall, co-pol channels tend to show similar sensitivity patterns across different parameters, with some Sh differences between $\mathrm{HH}$ and $\mathrm{VV}$ for plant density $\left(\mathrm{P}_{\text {dens }}\right)$ and water content $\left(\mathrm{P}_{\mathrm{mv}}\right)$. Out of all polarizations, the only one showing some sensitivity to change in incidence angle $\theta$ is $\mathrm{HV}$, with a Shapley effect of 0.17 , the second highest after that of plant height in this polarization. For what concerns the prominent role of plant (stem) height, followed by leaf length, our results are generally consistent with the only other work available in literature on variance-based sensitivity analysis of rice backscattering [21]. On the other hand, the experimental setup adopted by Yuzugullu et al. [21], i.e. running GSA separately for different phenology stages, is quite different from the one here adopted and findings are not easy to be compared in a direct way. At the same time, compared to the findings of [21] our work refined the analysis of X-band rice backscattering drivers by explicitly accounting for model input correlations through Shapley effects, and enlarged the scope of the sensitivity spectrum by taking into account leaf angle distribution and incidence angle variability.

The assessment of PRCC scores (Supplementary Fig. S7-S8) provides further insights into rice X-band backscattering, distinctly for young plants $\left(\mathrm{P}_{\text {height }}<0.4 \mathrm{~m}\right)$ and maturing ones $\left(\mathrm{P}_{\text {height }} \geq 0.4 \mathrm{~m}\right)$. For young plants, $\sigma^{\circ} \mathrm{VV}$ shows negative correlation with plant density $(\mathrm{PRCC}=-0.27)$, and is inversely related to stem radius (for $\theta=30-50^{\circ}$ ), 
while $\sigma^{\circ} \mathrm{HH}$ is positively correlated with stem radius $(\mathrm{PRCC}=+0.36)$, and plant height $(\mathrm{PRCC}>+0.21$, especially for $\theta=20-40^{\circ}$ ). This implies that during early growth, rice vertical scattering decreases with canopy density and stem growth, which is possibly due to increase in attenuation as dominant factor; instead, horizontal scattering is mainly shaped by double bounce driven by stems, which is typical of paddy rice growing over flooded background [13],[42]. For maturing plants, $\sigma^{\circ} \mathrm{VV}$ results to be highly biased by the overestimation of vertical attenuation in RTM outputs (as discussed in section III, Fig. 2b) and sensitivity scores derived (Sh or PRCC) do not provide a realistic picture of rice fields behaviour. Backscattering in $\mathrm{HH}$ pol tends to decrease with plant height and plant density (PRCC $<-0.36)$, as well as with $\theta(\mathrm{PRCC}=-0.36)$, while it correlates positively with plant water content $\left(\mathrm{PRCC}>+0.37\right.$ for $\left.\theta=30-50^{\circ}\right)$. Apart from its extreme sensitivity to $\theta(\mathrm{PRCC}=-0.75) \sigma^{\circ} \mathrm{HV}$ generally behaves more similarly to $\sigma^{\circ} \mathrm{HH}$ than to $\sigma^{\circ} \mathrm{VV}$ in terms of sensitivity to crop morphology (ALA set aside).

TABLE I

SHAPLEY EFFECTS OF RICE CONDITIONS ON X-BAND $\sigma^{\circ}$

\begin{tabular}{|c|c|c|c|c|c|c|c|c|c|c|}
\hline$\theta$ & Pol & $\mathbf{P}_{\text {height }}$ & $\mathbf{S}_{\mathrm{rad}}$ & $\mathbf{P}_{\mathrm{mv}}$ & $\mathbf{P}_{\text {dens }}$ & $\mathbf{N}_{\text {leaves }}$ & ALA & $\begin{array}{c}\mathbf{a} \mathbf{1}_{\text {leave }} \\
\mathrm{s}\end{array}$ & $\begin{array}{c}\mathbf{a} 2_{\text {leave }} \\
\mathrm{s}\end{array}$ & $\theta$ \\
\hline \multirow{4}{*}{ all } & VV & 0.27 & 0.13 & 0.06 & 0.12 & 0.08 & 0.03 & 0.18 & 0.13 & 0.02 \\
\hline & $\mathrm{HH}$ & 0.26 & 0.12 & 0.10 & 0.05 & 0.07 & 0.06 & 0.16 & 0.13 & 0.05 \\
\hline & $\mathrm{VH}$ & 0.27 & 0.13 & 0.08 & 0.06 & 0.08 & 0.03 & 0.17 & 0.13 & 0.05 \\
\hline & $\mathrm{HV}$ & 0.24 & 0.11 & 0.07 & 0.07 & 0.06 & 0.02 & 0.15 & 0.11 & 0.17 \\
\hline \multirow{4}{*}{$20^{\circ}$} & VV & 0.28 & 0.13 & 0.09 & 0.11 & 0.07 & 0.00 & 0.17 & 0.15 & - \\
\hline & $\mathrm{HH}$ & 0.27 & 0.13 & 0.10 & 0.09 & 0.07 & 0.05 & 0.15 & 0.14 & - \\
\hline & $\mathrm{VH}$ & 0.29 & 0.14 & 0.09 & 0.04 & 0.07 & 0.04 & 0.18 & 0.15 & - \\
\hline & $\mathrm{HV}$ & 0.28 & 0.14 & 0.09 & 0.10 & 0.06 & 0.03 & 0.16 & 0.14 & - \\
\hline \multirow{4}{*}{$30^{\circ}$} & VV & 0.28 & 0.14 & 0.07 & 0.15 & 0.07 & 0.00 & 0.17 & 0.14 & - \\
\hline & $\mathrm{HH}$ & 0.27 & 0.14 & 0.11 & 0.08 & 0.06 & 0.04 & 0.16 & 0.14 & - \\
\hline & $\mathrm{VH}$ & 0.29 & 0.15 & 0.09 & 0.08 & 0.07 & 0.01 & 0.18 & 0.15 & - \\
\hline & HV & 0.30 & 0.14 & 0.09 & 0.10 & 0.07 & 0.00 & 0.17 & 0.14 & - \\
\hline \multirow{4}{*}{$40^{\circ}$} & VV & 0.27 & 0.14 & 0.06 & 0.14 & 0.07 & 0.00 & 0.18 & 0.15 & - \\
\hline & $\mathrm{HH}$ & 0.27 & 0.13 & 0.11 & 0.06 & 0.08 & 0.04 & 0.17 & 0.14 & - \\
\hline & $\mathrm{VH}$ & 0.27 & 0.15 & 0.08 & 0.09 & 0.08 & 0.02 & 0.17 & 0.14 & - \\
\hline & HV & 0.29 & 0.15 & 0.08 & 0.10 & 0.06 & -0.01 & 0.18 & 0.15 & - \\
\hline \multirow{4}{*}{$50^{\circ}$} & VV & 0.27 & 0.15 & 0.05 & 0.09 & 0.07 & 0.04 & 0.19 & 0.14 & - \\
\hline & $\mathrm{HH}$ & 0.27 & 0.14 & 0.11 & 0.06 & 0.08 & 0.04 & 0.17 & 0.14 & - \\
\hline & $\mathrm{VH}$ & 0.26 & 0.15 & 0.08 & 0.06 & 0.09 & 0.04 & 0.17 & 0.15 & - \\
\hline & HV & 0.30 & 0.16 & 0.07 & 0.07 & 0.07 & 0.00 & 0.18 & 0.15 & - \\
\hline
\end{tabular}

TABLE II

SHAPLEY EFFECTS OF MAIZE CONDITIONS ON X-BAND $\sigma^{\circ}$

\begin{tabular}{|c|c|c|c|c|c|c|c|c|c|c|}
\hline$\theta$ & Pol & $\mathbf{P}_{\text {height }}$ & $\mathbf{S}_{\mathrm{rad}}$ & $\mathbf{P}_{\mathbf{m v}}$ & $\mathbf{P}_{\text {dens }}$ & $\mathbf{N}_{\text {leaves }}$ & ALA & \multicolumn{2}{|c|}{$\mathbf{a} \mathbf{1}_{\text {leave }} \mathbf{a} \mathbf{2}_{\text {leave }}$} & $\boldsymbol{\theta}$ \\
\hline \multirow{4}{*}{ all } & VV & 0.12 & 0.03 & 0.05 & 0.01 & 0.05 & 0.33 & 0.06 & 0.03 & 0.31 \\
\hline & $\mathrm{HH}$ & 0.12 & 0.04 & 0.06 & 0.01 & 0.05 & 0.35 & 0.06 & 0.03 & 0.28 \\
\hline & $\mathrm{VH}$ & 0.19 & 0.04 & 0.12 & 0.02 & 0.08 & 0.22 & 0.06 & 0.04 & 0.23 \\
\hline & $\mathrm{HV}$ & 0.19 & 0.04 & 0.13 & 0.01 & 0.07 & 0.21 & 0.07 & 0.04 & 0.23 \\
\hline \multirow{4}{*}{$20^{\circ}$} & VV & 0.29 & 0.12 & 0.04 & 0.01 & 0.21 & 0.04 & 0.17 & 0.11 & - \\
\hline & $\mathrm{HH}$ & 0.29 & 0.12 & 0.04 & 0.01 & 0.22 & 0.04 & 0.17 & 0.11 & - \\
\hline & $\mathrm{VH}$ & 0.33 & 0.11 & 0.05 & 0.02 & 0.22 & 0.00 & 0.17 & 0.10 & - \\
\hline & $\mathrm{HV}$ & 0.33 & 0.11 & 0.04 & 0.01 & 0.23 & 0.00 & 0.17 & 0.10 & 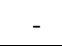 \\
\hline \multirow{4}{*}{$30^{\circ}$} & $\mathrm{VV}$ & 0.19 & 0.07 & 0.05 & 0.00 & 0.08 & 0.43 & 0.11 & 0.06 & - \\
\hline & $\mathrm{HH}$ & 0.19 & 0.08 & 0.05 & 0.00 & 0.09 & 0.43 & 0.10 & 0.07 & - \\
\hline & $\mathrm{VH}$ & 0.23 & 0.05 & 0.14 & 0.01 & 0.06 & 0.38 & 0.08 & 0.05 & - \\
\hline & $\mathrm{HV}$ & 0.22 & 0.06 & 0.14 & 0.01 & 0.06 & 0.37 & 0.09 & 0.05 & - \\
\hline \multirow{4}{*}{$40^{\circ}$} & VV & & 0.02 & 0.06 & 0.00 & 0.03 & 0.71 & 0.05 & 0.02 & - \\
\hline & $\mathrm{HH}$ & 0.11 & 0.03 & 0.05 & 0.00 & 0.04 & 0.70 & 0.05 & 0.02 & - \\
\hline & $\mathrm{VH}$ & 0.20 & 0.04 & 0.17 & 0.00 & 0.05 & 0.44 & 0.06 & 0.04 & - \\
\hline & $\mathrm{HV}$ & 0.20 & 0.04 & 0.17 & 0.01 & 0.05 & 0.44 & 0.06 & 0.04 & - \\
\hline \multirow{4}{*}{$50^{\circ}$} & VV & 0.17 & 0.02 & 0.13 & 0.00 & 0.03 & 0.58 & 0.03 & 0.05 & - \\
\hline & $\mathrm{HH}$ & 0.16 & 0.03 & 0.12 & 0.01 & 0.03 & 0.59 & 0.03 & 0.04 & \\
\hline & $\mathrm{VH}$ & 0.25 & 0.04 & 0.24 & 0.01 & 0.05 & 0.31 & 0.05 & 0.06 & - \\
\hline & $\mathrm{HV}$ & 0.24 & 0.04 & 0.23 & 0.00 & 0.05 & 0.31 & 0.06 & 0.06 & - \\
\hline
\end{tabular}

Variance-based sensitivity computed as Shapley effects scores of X-band $\sigma^{\circ}$ modelled outputs to maize biophysical conditions. $P_{\text {height }}=$ plant height, $S_{\text {rad }}$ $=$ stem radius, $\mathrm{P}_{\mathrm{mv}}=$ plant water content, $\mathrm{P}_{\text {dens }}=$ plant density, $\mathrm{N}_{\text {leaves }}=$ number of leaves per plant, $\mathrm{ALA}=$ average leaf angle, $\mathrm{a} 1_{\text {leaves }}$ leaf half-length, $\mathrm{a} 2_{\text {leaves }}$ $=$ leaf half-width, $\theta=$ incidence angle.

This suggests that cross-pol backscattering for maturing rice is prevalently shaped by horizontal polarized components, which are escaping volumetric attenuation in canopy more easily than vertical scattering.

Due to the fact that our RTM did not account for panicles, sensitivity results for rice should be theoretically considered limited to rice plants before flowering phase starts, i.e. with panicles emerged and approximately vertical, which could be roughly assimilated to a prolongation of stems.

Table 2 summarizes sensitivity of $X$-band $\sigma^{\circ}$ over maize. In particular, Sh scores highlight the primary role taken by the mutual interaction of ALA and incidence angle $\theta$ in determining total $\sigma^{\circ}$, which jointly cover $63.0-64.4 \%$ and 
$44.9 \%$ of total backscattering variance, respectively in co-pol and cross-pol channels. This pattern is related to the typical morphological characteristics of maize, with medium-size leaves and plagiophile canopy $\left(\mathrm{a} 1_{\text {leaves }} / \mathrm{a} 2_{\text {leaves }}=8\right.$ on average; measured ALA $\left.=51 \pm 11^{\circ}\right)$. Plant height and water content $\left(\mathrm{P}_{\text {height }}, \mathrm{P}_{\mathrm{mv}}\right)$ contribute to a secondary, yet nonnegligible part of remaining $\sigma^{\circ}$ variability, especially in cross-pol where they cover another $31.1-31.7 \%$ of variance. Co-pol channels tend to show similar sensitivity patterns, with ALA modulating scattering from leaves at medium to high angles $\left(\theta=30-50^{\circ}\right)$ and Sh scores in the range 0.43-0.71, while plant height assumes some relevance $(\mathrm{Sh}=0.19$ 0.29 ) with low, steeper angles $\left(\theta=20-30^{\circ}\right)$. Compared to co-pol, $\sigma^{\circ} \mathrm{HV}$ (very similar to $\sigma^{\circ} \mathrm{VH}$ ) partly escapes overloading of leaf scattering due to angular effects, and shows a little more sensitivity to plant height and water content, scoring Shapley effects of 0.18 and 0.13 , respectively.

Although no evidence of previous works applying variance-based sensitivity analysis to maize backscattering was found, the observed patterns showed some overlapping with findings in [43] and [44], but they don't cover secondary backscattering mechanisms. Due to the incorporation of second order interactions, our results clearly show that primary mechanism composing total X-band backscatter in maize are connected to volume scattering from leaves (through their inclination), under a range of incidence angles of $\theta=30-50^{\circ}$. Again, the assessment of PRCC scores (Supplementary Fig. S9-S10) provides further insights into maize X-band backscattering, distinguishing young plants $\left(\mathrm{P}_{\text {height }}<1.5 \mathrm{~m}\right)$ from maturing ones $\left(\mathrm{P}_{\text {height }} \geq 1.5 \mathrm{~m}\right)$. For young plants, co-pol channels $\sigma^{\circ} \mathrm{VV}$ and $\sigma^{\circ} \mathrm{HH}$ generally respond negatively to leaf angle distribution ( $\mathrm{PRCC}=-0.40$ ), with different behaviours depending on incidence angle. Leaf scattering dominates at intermediate $\theta\left(30-40^{\circ}\right)$, not far from the typical young maize ALA $\left(30-50^{\circ}\right)$, while stem attenuation and leaf scattering tend to mutually balance at $\theta=50^{\circ}$. In cross-pol channels, overall patterns are not much different, with higher correlations for ALA $(\mathrm{PRCC}=-0.57)$ and plant water content $(\mathrm{PRCC}=+0.28)$. For maturing plants, $\sigma^{\circ} \mathrm{VV}$ and $\sigma^{\circ} \mathrm{HH}$ dependence on ALA is slightly more marked than for younger plants (PRCC $<-0.55$ ), and it is positively correlated to $\theta$ (PRCC $>+0.44)$. The variation in sensitivity with incidence angle is different than in early growth phase, due to ALA values (50-70 $)$ typically higher in mature maize plants: at $\theta=20^{\circ}$, attenuation is driven more by stems than leaves; at intermediate $\theta=30-40^{\circ}$, leaf scattering still dominates, and at shallow $\theta=50^{\circ}$, plant water content takes a relevant role $(\mathrm{PRCC}>+0.33$ ) in moving the balance of canopy attenuation and leaf scattering. Cross-pol channels behave similarly to co-pol, with higher sensitivity $(\mathrm{PRCC}>+0.61)$ to plant water content at intermediate angles $\left(\theta=30-40^{\circ}\right)$.

Again, the formulation of RTM we used did not account for maize ears and our findings in terms of sensitivity analysis should be theoretically considered limited to maize plants before ripening phase starts. Other studies have taken into account the influence of soil moisture [45]-[47], but they concluded that this influence is lower for higher frequencies (such as X-band), and limited to maize plants before canopy closure (i.e. for $\mathrm{P}_{\text {height }}<1 \mathrm{~m}$ ). 

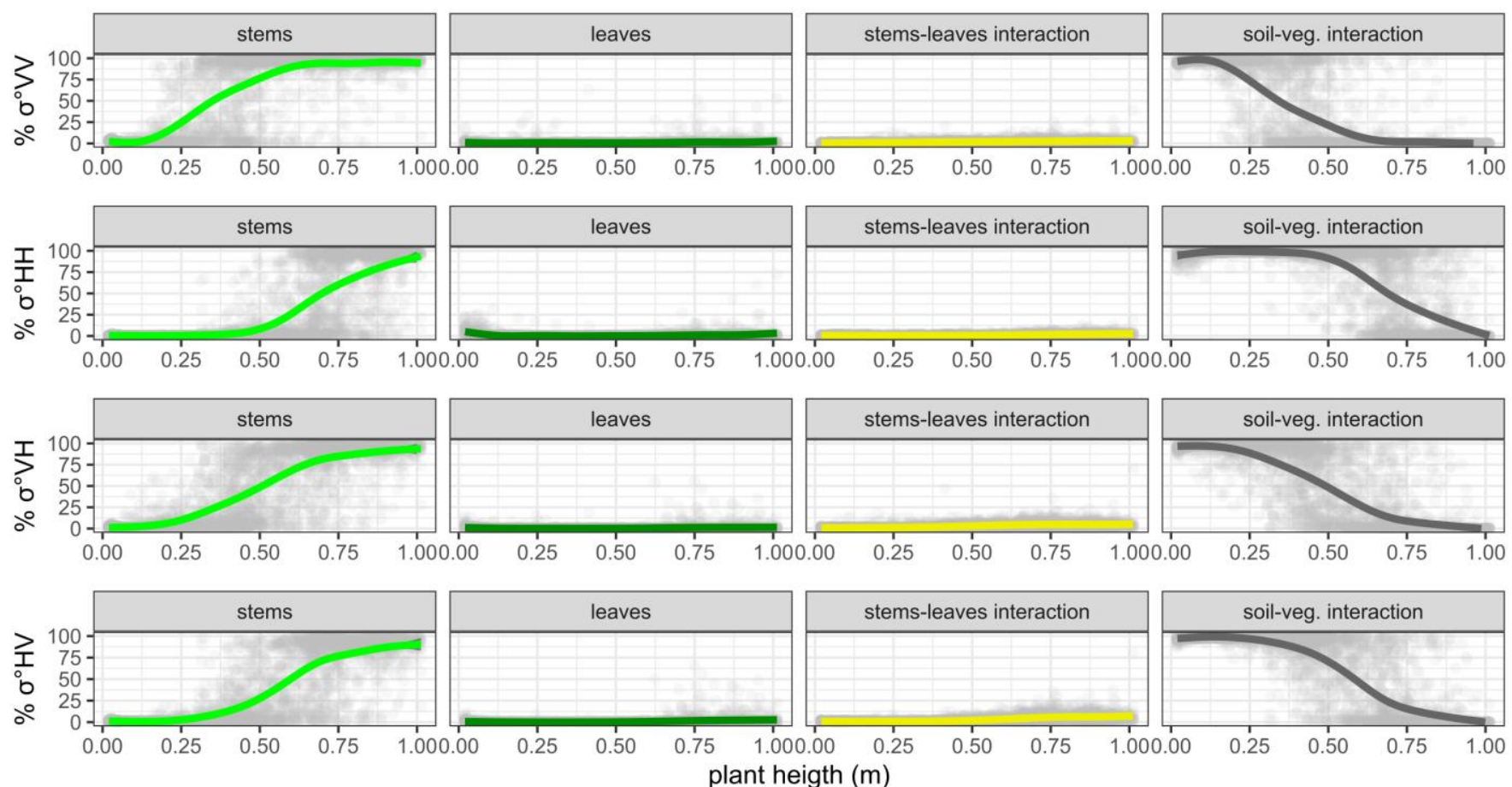

Fig. 3, Contributions of stems, leaves, stems-leaves interaction and (flooded) soil-vegetation interaction to X-band $\sigma^{\circ}$ of rice fields, expressed in percentage of total $\sigma^{\circ}$ as a function of plant height, in different polarizations. A common observation configuration is assumed with $\theta=40^{\circ}$. Grey dots represent all simulated points at this incident angle $(\mathrm{N}=3000)$, and colored lines are superimposed LOESS fit for all simulations.
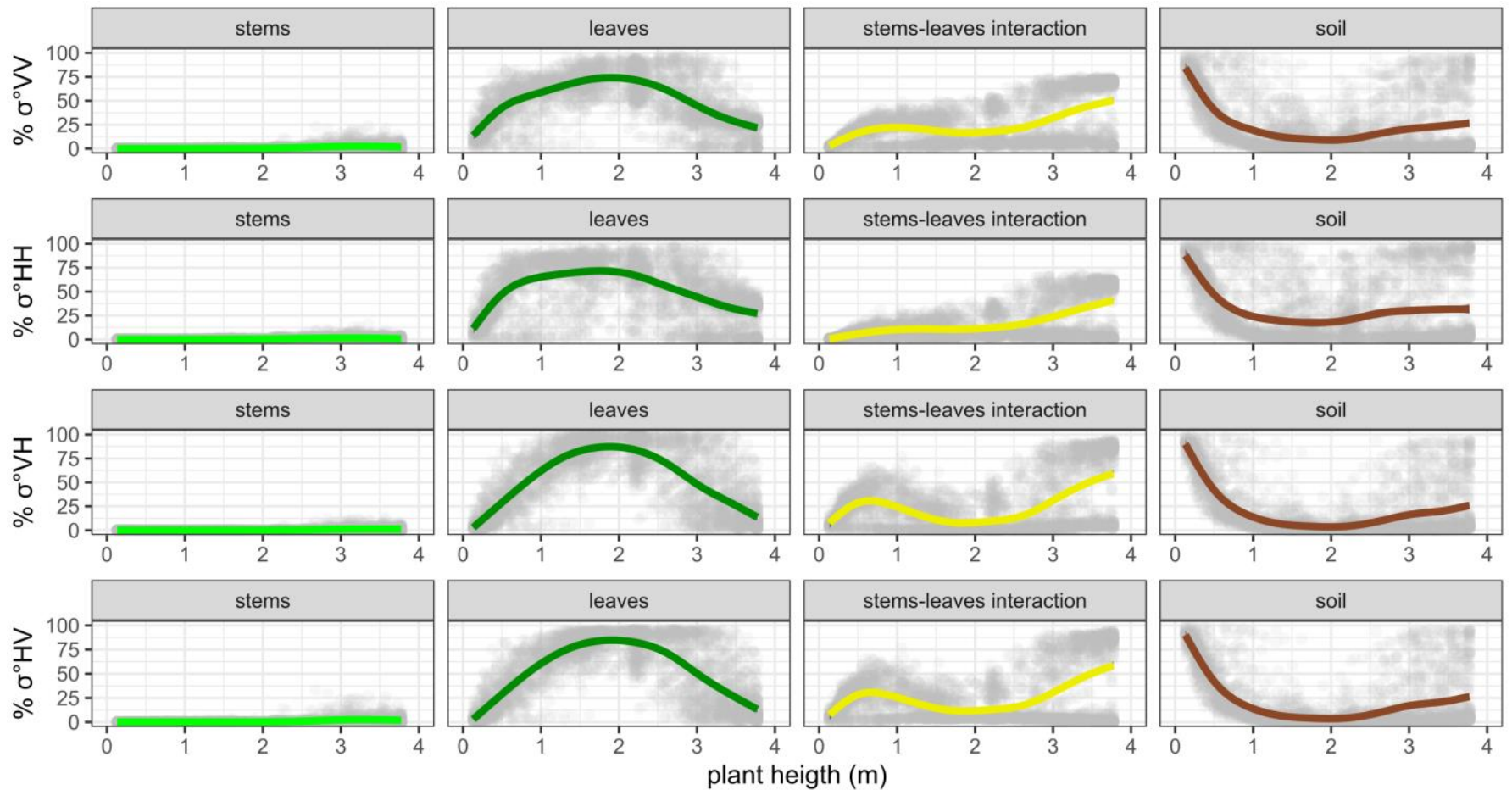

Fig. 4. Contributions of stems, leaves, stems-leaves interaction and soil to X-band $\sigma^{\circ}$ of maize fields, expressed in percentage of total $\sigma^{\circ}$ as a function of plant height, in different polarizations. A common observation configuration is assumed with $\theta=40^{\circ}$. Grey dots represent all simulated points at this incident angle $(\mathrm{N}=3000)$, and colored lines are superimposed LOESS fit for all simulations. 


\section{Contributions of different scattering mechanisms}

Fig. 3 shows the relative contribution of different components to total $\sigma^{\circ}$ in X-band of rice fields, observed under an incidence angle of $40^{\circ}$. With canopy background prevalently constituted by water layering over soil, the dominant contribution is the soil-vegetation interaction, commonly called double bounce [13],[48], which reaches over 90\% for plants up to $0.2 \mathrm{~m}$ high in VV pol, and up to $0.5-0.6 \mathrm{~m}$ high in $\mathrm{HH}$ (varying on $\theta$ ). Different behaviours in vertical and horizontal scattering are due to changes in balance between double bounce and volumetric attenuation for the two polarizations and show that the former dominates total $\mathrm{X}$-band $\sigma^{\circ}$ for a longer time span during paddy rice vegetative phase [13],[49]. Double bounce scattering is greatly amplified by the presence of water as canopy background in rice paddies. Sensitivity analysis mainly attributes it to vertical and near-vertical elements in the first stages of growth with stems and narrow-erect leaves of rice plants representing most of total $\sigma^{\circ}$ sensitivity $(\mathrm{Sh}>0.4)$.

When crop canopy become higher (and denser), total X-band backscattering tends to decrease as volume attenuation from the canopy gets prominence as the main factor, and $\sigma^{\circ}$ is then driven by direct scattering from stems, although with low absolute magnitude $(<-20 \mathrm{~dB})$. Leaf scattering provides minimal contribution to total backscattering (generally lower than 5\%), with some minor effect only when lower rice ALA (at beginning and late phases of development) combines with shallow $\theta\left(40-50^{\circ}\right)$, especially in VV pol. Stems-leaves interaction, represented by second order RTM components, also have minimal effects on total backscatter, thus providing an explanation on why accounting for second order interactions does not sensibly enhance the performance of RTM for rice. Contributions of different components to total X-band $\sigma^{\circ}$ in $\mathrm{HV}$ polarization tends to behave in intermediate way between horizontal and vertically polarized components.

Fig. 4 shows the relative contribution of different components to total $\sigma^{\circ}$ in X-band of maize fields (planted in rows with densities under 10 plants $/ \mathrm{m}^{2}$ ), observed under an incidence angle of $40^{\circ}$. For plants shorter than $0.5 \mathrm{~m}$, the dominant scattering mechanism is the soil scattering attenuated by vegetation biomass, which decreases with plant growth, contributing more than $50 \%$ of total backscattering all over different polarizations, and gradually becoming negligible for $\mathrm{P}_{\text {height }}>1 \mathrm{~m}$, generally in line with published works [45]-[46]. As plants grow and maize biomass increases, the contribution of scattering from canopy elements becomes more and more relevant. In particular, mediumsized leaves of plagiophile maize roughly contribute more than $50 \%$ of total $\sigma^{\circ}$ for plants between 1 and $3 \mathrm{~m}$ high, reaching a peak around $80 \%$ for $2 \mathrm{~m}$ high plants (i.e. in stem elongation phase, before flowering). Contributions to total backscattering by stems is instead minimal, generally lower than 5-10\%; stems play a role within second order RTM components, incising more on shallow $\theta\left(40-50^{\circ}\right)$, with stems-leaves interaction covering up to $20-40 \%$ total backscattering for plants higher than $3 \mathrm{~m}$. Backscattering in cross-pol channels is even more unbalanced towards direct leaf and stems-leaves interactions components than co-pol channels, even if absolute $\sigma^{\circ}$ tends to get below $-25 \mathrm{~dB}-$ i.e. under NESZ for most spaceborne SAR systems - already when maize $\mathrm{P}_{\text {height }}>1 \mathrm{~m}$.

Insights into the relative importance of different scattering mechanisms and of their drivers in terms of crop biophysical parameter are provided by variance-based sensitivity analysis expressed as Shapley effects of each individual component (Fig. 5). In rice (Fig. 5a), the soil-vegetation interaction, as the main driver of total backscatter, generally displays Shapley effect scores similar to those of total $\sigma^{\circ}$ (Table 1), once more highlighting the particular 
sensitivity to vertical and pseudo-vertical elements of rice canopy (stem length and diameter, leaf length). Of stem size, diameter is the most influencing one, while for stems-leaves interaction all parameters have roughly the same importance. In maize (Fig. 5b), the contribution of leaf scattering in co-pol channels is extremely sensitive to joint variation of observation angle and average leaf inclination, peaking in magnitude when $\theta$ and ALA values are similar (i.e. mutual differences average under $20^{\circ}$ ). In cross-pol channels, X-band backscattering mainly responds to incidence angle only $(\mathrm{Sh}>0.5)$. The fact that leaves and stems-leaves interaction display similar patterns of sensitivity - mainly driven by the combination of ALA and $\theta$ (Fig. 5b) - together with virtually null contribution of stems alone to total backscattering, suggests that leaves, for their number and size in maize, play the main role in the second order interaction with stems. The contribution of soil background (attenuated by vegetation) tend to respond to variability in observation angle, as well as parameters connected to plant biomass and LAI (plant height, leaf number and size).

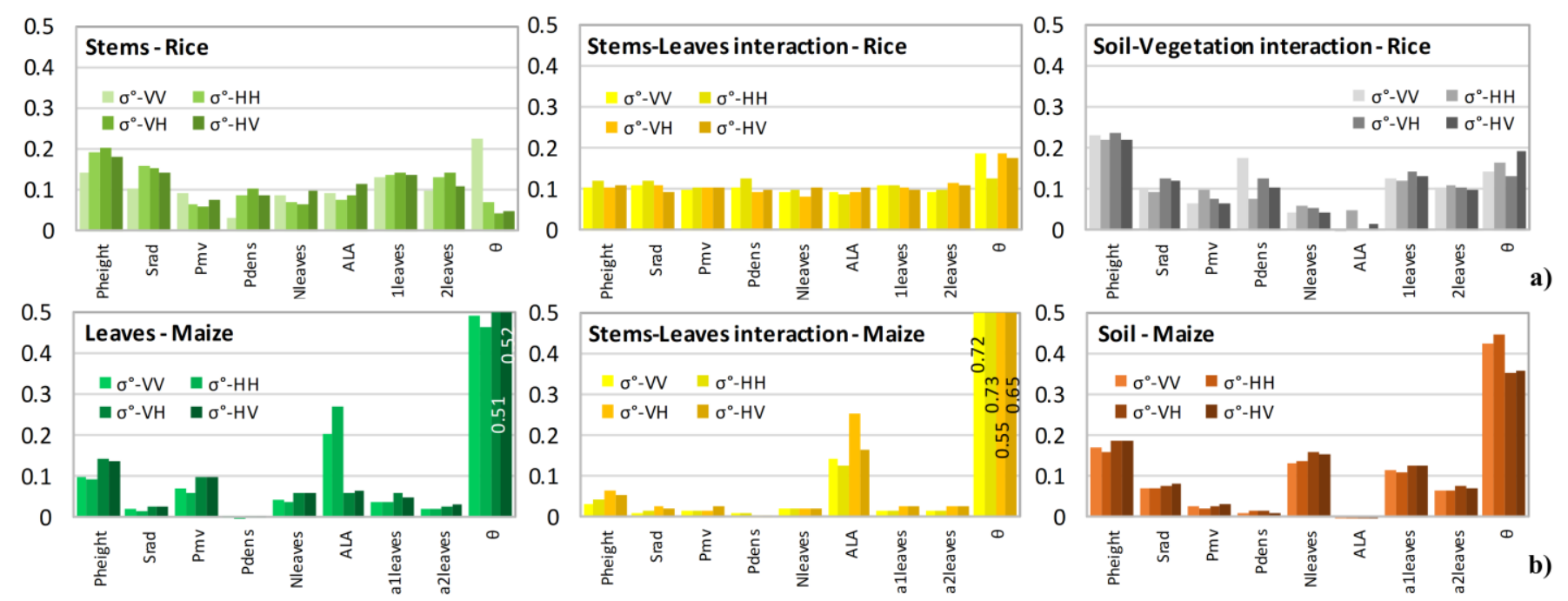

Fig. 5. Variability of Shapley effects scores of X-band $\sigma^{\circ}$ modelled outputs to RTM input parameters for different canopy-ground system contributions (stems, leaves, stems-leaves interactions, and ground contribution): in (a) rice and (b) maize. Plots for rice leaves and maize stems are not shown because of their virtually null contribution to total backscatter.
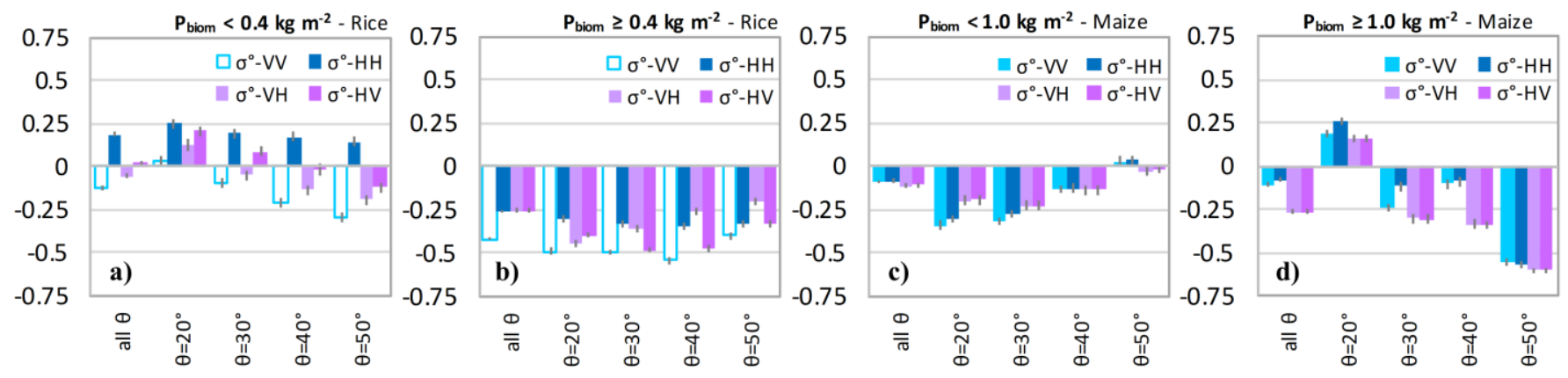

Fig. 6. Variability of PRCC of X-band $\sigma^{\circ}$ to modelled crop biomass with changing $\theta$ (from $20^{\circ}$ to $50^{\circ}$ ), calculated for rice, separately for plants biomass (a) $<0.4 \mathrm{~kg} \mathrm{~m}^{-2}$ and (b) $\geq 0.4 \mathrm{~kg} \mathrm{~m}^{-2}$, and for maize, separately for plant biomass (c) $<1.0 \mathrm{~kg} \mathrm{~m}^{-2}$ and (d) $\geq 1.0 \mathrm{~kg} \mathrm{~m}^{-2}$

\section{Sensitivity of $X$-band backscatter to crop biomass}

Sensitivity of X-band backscattering to standing crop biomass for rice and maize is revealed in Fig. 6 through PRCC plotted for different incidence angles, distinctly for young and maturing plants (see variability of total $\sigma^{\circ}$ with biomass 
in Supplementary Fig. S11-S12). For young rice plants $\left(\mathrm{P}_{\text {biom }}<0.4 \mathrm{~kg} \mathrm{~m}^{-2}\right), \mathrm{HH}$ is the only polarization with consistently positive correlation $v s$. plant biomass for all $\theta(\mathrm{PRCC}=+0.19)$, peaking at $\mathrm{PRCC}=+0.25$ for $\theta=20^{\circ}$ (Fig. $6 \mathrm{a})$, while in maturing rice $\left(\mathrm{P}_{\text {biom }} \geq 0.4 \mathrm{~kg} \mathrm{~m}^{-2}\right)$ all polarizations show negative correlations with biomass, with more or less strength (Fig. 6b). This confirms previous findings about correlation between X-band $\sigma^{\circ}$ and plant biophysical parameters (LAI, biomass), observed only for early growth stages [49]-[50]. Since rice backscattering generally falls below the common NESZ threshold for spaceborne SAR data in all polarizations but HH (Supplementary Fig. S11), the latter seems to provide the only feasible option at the current state of technology available for directly estimating crop biomass in X-band with operational potential $(-0.35<\mathrm{PRCC}<-0.30)$ in mature rice fields, particularly at intermediate $\theta=30-40^{\circ}$. For maize, the selection of the optimal incidence angle strongly depends on the growth stage, and plays a crucial role in the sensitivity to plant biomass is to be maximised, even if correlations are not consistently strong, as already shown in [43]. In young plants, the best correlations (PRCC <-0.27) are scored for co-pol $\sigma^{\circ}$ under steep angles $\left(\theta=20-30^{\circ}\right.$, Fig. 6c), while in maturing plants, highest correlations (PRCC < -0.55$)$ are found using shallow angles $\left(\theta=50^{\circ}\right.$, Fig. $\left.6 \mathrm{~d}\right)$, independently of polarizations. The complex backscattering mechanisms behind this pattern, coming out of joint effects of different plant parameters incorporated into maize biomass dynamics, need further investigation, but at the moment we can hypothesize a possible explanation could again be found in the interaction between ALA (which is lower in younger than in mature maize plants) and $\theta$. The prevalence of direct scattering from leaves under certain angular configurations ends up in masking out volume attenuation effect, which is more directly connected to canopy density and biomass.
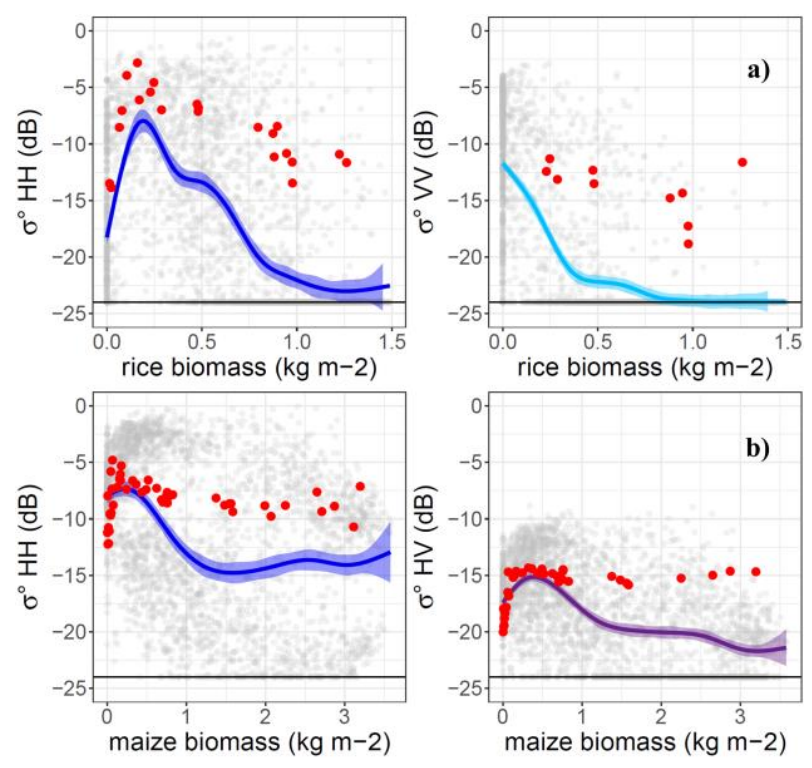

Fig. 7. Variation of X-band $\sigma^{\circ}$ modelled outputs with crop biomass at $\theta=40^{\circ}$ (grey dots), with superimposed LOESS fit and TSX measured backscatter over crop fields in North Italy, at $\theta=40^{\circ}$ (red dots), for: (a) rice (HH and VV polarizations), and (b) maize (HH and HV polarizations).

Within the range of dry biomass where canopy attenuation shows its principal effects, i.e. $0.15-1.10 \mathrm{~kg} \mathrm{~m}^{-2}$, the decrement of rice backscatter with biomass growth in HH approximately (LOESS fit, computed according to [51]) amounts to $1.4-1.6 \mathrm{~dB}$ per $100 \mathrm{~g} \mathrm{~m}^{-2}$ in RTM simulations $\left(\theta=40^{\circ}\right.$, restricted to $\sigma^{\circ}>-24 \mathrm{~dB}$ for taking into account NESZ of TSX), and to $0.8 \mathrm{~dB}$ per $100 \mathrm{~g} \mathrm{~m}^{-2}$ in TSX measured backscatter of North Italy paddy rice fields $\left(\theta=40^{\circ}\right.$, 
Fig. 7a). In the same range of biomass values and observation configuration, the decrement of total X-band backscatter in $\mathrm{HH}$ per $100 \mathrm{~g} \mathrm{~m}^{-2}$ of maize biomass is around half of what observed for rice, i.e. 0.6-0.7 $\mathrm{dB}$ in RTM simulations (LOESS fit) and $0.3 \mathrm{~dB}$ from TSX measured $\sigma^{\circ}$ (Fig. 7b). Due to the extreme sensitivity of maize backscatter to the joint variation of $\theta$ and ALA (in particular in co-pol channels), left panel of Fig. 7b shows two clusters of points, where simulations based on typical ALA of common maize varieties $\left(35-55^{\circ}\right)$ when $\theta=40^{\circ}$ tend to group with higher $\sigma^{\circ} \mathrm{HH}$ $(>-10 \mathrm{~dB})$ due to high direct scattering from leaves and leaves-stems interaction, while the other group of points are representative of maize varieties with near erectophile leaves (ALA $\left.=60-70^{\circ}\right)$, showing generally lower $\sigma^{\circ} \mathrm{HH}(<-10$ $\mathrm{dB}$ ) due to the predominance of canopy volume effect (attenuation). In this sense, the LOESS curve overlaid on Fig. $7 \mathrm{~b}$ do not represent a generalization of maize backscatter dynamics, but more a graphical synthesis of a broadly averaged behavior.

The saturation of simulated rice backscatter in $\mathrm{VV}$ pol for biomass lower than $0.40 \mathrm{~kg} \mathrm{~m}^{-2}$, a direct consequence of the underestimation of our modelling approach already mentioned in section III, is evident on right panel on Fig. 7a, and limits the practical considerations one can draw from our in silico dataset with respect to responsivity of vertically polarized backscatter to rice biomass in field conditions.

\section{CONCLUSIONS}

A comprehensive quantification of the sensitivity of X-band backscatter to agronomic and morphological characteristics of two globally relevant crops, maize and rice has been presented in this paper. To this end, variancebased sensitivity techniques applied to phenology-informed RTM simulations based on extensive empirical crop data collected in the field, jointly exploited with multi-temporal spaceborne SAR data (TerraSAR-X) were used.

The main outcomes of this work are summarized as follows:

i) The development of a second order model, incorporating interactions among canopy elements (stems and leaves), is needed to correctly interpret X-band SAR data on maize, while a single order model could be sufficient on rice. Nevertheless, the developed model is unable to correctly simulate the SAR data in very dense rice canopies (>900 stems m-2), due to overestimation of vertical attenuation.

ii) Phenology-informed model simulations based on crop biophysical parameters measured in situ allow to assess the main scattering mechanisms for rice and maize and to separate the relative contribution of various canopy elements under different polarizations and observation setups.

iii) Multidimensional global sensitivity analysis, explicitly accounting for model input correlations through Shapley effects, provides information about the relative proportion of total backscatter variance explained by different crop parameters, revealing: a) for rice, the different behaviour in vertical and horizontal polarizations and their changes throughout the plant growth cycle, and b) for maize, the mixed contribution of canopy density and leaf angle distribution, strongly depending on the incident angle.

iv) Extending model simulations with empirical allometric estimation of rice and maize biomass (on area basis) allows to highlight the capabilities of X-band SAR in estimating standing crop biomass, suggesting that, when canopy attenuation is a relevant factor $\left(0.15-1.10 \mathrm{~kg} \mathrm{~m}^{-2}\right)$ : a) $\mathrm{HH}$ polarization $\left(\theta=20-40^{\circ}\right)$ can be used for rice biomass 
estimation without approaching lower detection limits (NESZ), with a sensitivity over $0.8 \mathrm{~dB}$ per $100 \mathrm{~g} \mathrm{~m}^{-2}$, confirmed by real case TerraSAR-X data paddy fields in northern Italy; and b) outside early growth phases, the competition of leaf scattering and canopy attention prevents the use of a similar relationship in maize, with sensitivity reduced to less than half for rice, i.e. around $0.3 \mathrm{~dB}$ every $100 \mathrm{~g} \mathrm{~m}^{-2}$ (HH polarization).

v) Although the choice of not including ears into the RTM, thus not covering the late part of crop phenological cycle, constitutes a theoretical limitation of our findings in terms of sensitivity, our approach is nevertheless putting forward the knowledge of X-band crop backscatter drivers within a large part of the growing season $(\mathrm{BBCH}<80$ for maize, $\mathrm{BBCH}<60$ for rice), and could easily be refined with future inclusion of future microwave modelling advancements.

vi) Further advancements could focus on refining the RTM over rice tackling the underestimation of $\sigma^{\circ}$ certain canopy conditions, e.g. by taking into account stem clusterization effects and a reliable simulations of rice ears (and grains), extending the approach to other major crops (e.g. soybean, wheat), and running the sensitivity analysis at additional frequencies ( $\mathrm{C}$ down to $\mathrm{P}$ band).

\section{ACKNOWLEDGMENT}

The authors are grateful to the farms "Azienda Agricola Carlo Franchino" and "Società Agricola Costanzo Giovanni\&Agostino" for having hosted and actively supported fieldwork carried out in their fields in Rosasco. The authors thank Daniela Stroppiana (CNR-IREA) for the fruitful discussion during the preliminary phase of the work, and Alberto Crema, Giacinto Manfron and Francesco Nutini (CNR-IREA) for their help during fieldwork. TerraSARX data used were provided by DLR in the context TSX scientific proposals LAN2412 (2014), LAN2984 (2015) and LAN3228 (2016).

\section{REFERENCES}

[1] M. W. Rosegrant and S. A. Cline, “Global food security: challenges and policies”, Science, vol. 302, n. 5652, pp. 1917-1919, Dec. 2003, doi: 10.1126/science.1092958.

[2] H. J. S. Finch, A. M. Samuel, and G. P. F. Lane, "Precision Farming”, Chap. 10 in Lockhart \& Wiseman's Crop Husbandry Including Grassland (9th Edition), edited by Finch, H. J. S., A. M. Samuel, and G. P. F. Lane, Woodhead Publishing, 2014, pp. $235-244$.

[3] T. Le Toan, H. Laur, E. Mougin, and A. Lopes, "Multitemporal and dual-polarization observations of agricultural vegetation covers by Xband SAR images", IEEE Transactions on Geoscience and Remote Sensing, vol. 27, n. 6, pp. 709-718, Nov. 1989, doi: 10.1109/TGRS.1989.1398243.

[4] B. A. M. Bouman, "Crop parameter estimation from ground-based X-band (3-cm wave) radar backscattering data", Remote Sensing of Environment, vol. 37, n. 3, pp. 193-205, Sep. 1991, doi: 10.1016/0034-4257(91)90081-G.

[5] M. S. Moran, A. Vidal, D. Troufleau, Y. Inoue, and T. A. Mitchell, "Ku- and C-band SAR for discriminating agricultural crop and soil conditions", IEEE Transactions on Geoscience and Remote Sensing, vol. 36, n. 1, pp. 265-272, Jan. 1998, doi: 10.1109/36.655335.

[6] G. Macelloni, S. Paloscia, P. Pampaloni, F. Marliani, and M. Gai, "The relationship between the backscattering coefficient and the biomass of narrow and broad leaf crops", IEEE Transactions on Geoscience and Remote Sensing, vol. 39, n. 4, pp. 873-884, Apr. 2001, doi: $10.1109 / 36.917914$.

[7] J. M. Lopez-Sanchez, S. R. Cloude, and J. D. Ballester-Berman, "Rice phenology monitoring by means of SAR polarimetry at X-Band", IEEE Transactions on Geoscience and Remote Sensing, vol. 50, n. 7, pp. 2695-2709, Jul. 2012, doi: 10.1109/TGRS.2011.2176740. 
[8] C. Atzberger, "Advances in remote sensing of agriculture: context description, existing operational monitoring systems and major information needs", Remote Sensing, vol. 5, n. 2, pp. 949-981, Feb. 2013, doi: 10.3390/rs5020949.

[9] P. Villa, D. Stroppiana, G. Fontanelli, R. Azar, and P. A. Brivio, "In-season mapping of crop type with optical and X-Band SAR data: a classification tree approach using synoptic seasonal features", Remote Sensing, vol. 7, n. 10, pp. 12859-12886, Oct. 2015, doi: $10.3390 / \mathrm{rs} 71012859$.

[10] H. McNairn and J. Shang, "A review of multitemporal synthetic aperture radar (SAR) for crop monitoring", in Multitemporal Remote Sensing: Methods and Applications, Y. Ban, A c. di Cham: Springer International Publishing, 2016, pp. 317-340.

[11] L. Dingle-Robertson et al., "Synthetic aperture radar (SAR) image processing for operational space-based agriculture mapping", International Journal of Remote Sensing, vol. 41, n. 18, pp. 7112-7144, Sept. 2020, doi: 10.1080/01431161.2020.1754494.

[12] M. A. Karam, A. K. Fung, R. H. Lang, and N. S. Chauhan, “A microwave scattering model for layered vegetation”, IEEE Transactions on Geoscience and Remote Sensing, vol. 30, n. 4, pp. 767-784, Jul. 1992, doi: 10.1109/36.158872.

[13] J. M. Lopez-Sanchez, J. D. Ballester-Berman, and I. Hajnsek, "First results of rice monitoring practices in Spain by means of time series of TerraSAR-X dual-pol images", IEEE Journal of Selected Topics in Applied Earth Observations and Remote Sensing, vol. 4, n. 2, pp. 412-422, Jun. 2011, doi: 10.1109/JSTARS.2010.2047634.

[14] S. C. Steele-Dunne, H. McNairn, A. Monsivais-Huertero, J. Judge, P.-W. Liu, and K. Papathanassiou, "Radar remote sensing of agricultural canopies: a review", IEEE Journal of Selected Topics in Applied Earth Observations and Remote Sensing, vol. 10, n. 5, pp. 2249-2273, May. 2017, doi: 10.1109/JSTARS.2016.2639043.

[15] F. Vicente-Guijalba, T. Martinez-Marin, and J. M. Lopez-Sanchez, "Dynamical approach for real-time monitoring of agricultural crops", IEEE Transactions on Geoscience and Remote Sensing, vol. 53, n. 6, pp. 3278-3293, Jun. 2015, doi: 10.1109/TGRS.2014.2372897.

[16] R. D. Morris, A. Kottas, M. Taddy, R. Furfaro, and B. D. Ganapol, “A statistical framework for the sensitivity analysis of radiative transfer models", IEEE Transactions on Geoscience and Remote Sensing, vol. 46, n. 12, pp. 4062-4074, Dec. 2008, doi: 10.1109/TGRS.2008.2002026.

[17] A. Mousivand, M. Menenti, B. Gorte, and W. Verhoef, "Global sensitivity analysis of the spectral radiance of a soil-vegetation system", Remote Sensing of Environment, vol. 145, pp. 131-144, Apr. 2014, doi: 10.1016/j.rse.2014.01.023.

[18] P. Villa, A. Mousivand, and M. Bresciani, "Aquatic vegetation indices assessment through radiative transfer modeling and linear mixture simulation", International Journal of Applied Earth Observation and Geoinformation, vol. 30, pp. 113-127, Aug. 2014, doi: 10.1016/j.jag.2014.01.017.

[19] Y. Xiao, W. Zhao, D. Zhou, and H. Gong, "Sensitivity analysis of vegetation reflectance to biochemical and biophysical variables at leaf, canopy, and regional scales", IEEE Transactions on Geoscience and Remote Sensing, vol. 52, n. 7, pp. 4014-4024, Jul. 2014, doi: 10.1109/TGRS.2013.2278838.

[20] C. Ma, X. Li, J. Wang, C. Wang, Q. Duan, and W. Wang, "A comprehensive evaluation of microwave emissivity and brightness temperature sensitivities to soil parameters using qualitative and quantitative sensitivity analyses", IEEE Transactions on Geoscience and Remote Sensing, vol. 55, n. 2, pp. 1025-1038, Feb. 2017, doi: 10.1109/TGRS.2016.2618903.

[21] O. Yuzugullu, S. Marelli, E. Erten, B. Sudret, and I. Hajnsek, "Determining rice growth stage with X-Band SAR: a metamodel based inversion", Remote Sensing, vol. 9, n. 5, pag. 460, May. 2017, doi: 10.3390/rs9050460.

[22] E. Erten, G. Taşkin, and J. M. Lopez-Sanchez, "Selection of PolSAR observables for crop biophysical variable estimation with global sensitivity analysis", IEEE Geoscience and Remote Sensing Letters, vol. 16, n. 5, pp. 766-770, May. 2019, doi: 10.1109/LGRS.2019.2891953.

[23] Food and Agriculture Organization of the United Nations (FAO), Crops, Livestock and Food Statistics (CLFS) Team, Rome, Italy [Online]. Available: http://www.fao.org/faostat/en/\#data, Accessed on: Feb 6, 2021.

[24] U. Meier, “Growth stages of mono- and dicotyledonous plants”. BBCH Monograph. Quedlinburg, Germany, Open Agrar Repositorium, 2018, doi: 10.5073/20180906-074619. 
[25] G. Fontanelli, R. Azar, and P. Villa, "CROP-X BIOPAR dataset for assessing sensitivity of X-band SAR backscatter to summer crop biophysical parameters from 2014 to 2016". Accessed: May 5, 2021 [Online]. Available at: https://doi.pangaea.de/10.1594/PANGAEA.894986.

[26] H. Breit, T. Fritz, U. Balss, M. Lachaise, A. Niedermeier, and M. Vonavka, "TerraSAR-X SAR processing and products", IEEE Transactions on Geoscience and Remote Sensing, vol. 48, n. 2, pp. 727-740, Feb. 2010, doi: 10.1109/TGRS.2009.2035497.

[27] S. Paloscia et al., "The sensitivity of Cosmo-SkyMed backscatter to agricultural crop type and vegetation parameters", IEEE Journal of Selected Topics in Applied Earth Observations and Remote Sensing, vol. 7, n. 7, pp. 2856-2868, Jul. 2014, doi: 10.1109/JSTARS.2014.2345475.

[28] T. Liao, S. Kim, S. Tan, L. Tsang, C. Su and T. J. Jackson, "Multiple scattering effects with cyclical correction in active remote sensing of vegetated surface using vector radiative transfer theory" in IEEE Journal of Selected Topics in Applied Earth Observations and Remote Sensing, vol. 9, no. 4, pp. 1414-1429, Apr. 2016, doi: 10.1109/JSTARS.2015.2505638.

[29] M. A. Karam and A. K. Fung, "Electromagnetic scattering from a layer of finite length, randomly oriented, dielectric, circular cylinders over a rough interface with application to vegetation”, International Journal of Remote Sensing, vol. 9, n. 6, pp. 1109-1134, Jun. 1988, doi: $10.1080 / 01431168808954918$.

[30] M. A. Karam and A. K. Fung, "Leaf-shape effects in electromagnetic wave scattering from vegetation", IEEE Transactions on Geoscience and Remote Sensing, vol. 27, n. 6, pp. 687-697, Nov. 1989, doi: 10.1109/TGRS.1989.1398241.

[31] F. T. Ulaby and M. A. El-rayes, "Microwave dielectric spectrum of vegetation - part II: dual-dispersion model", in IEEE Transactions on Geoscience and Remote Sensing, vol. GE-25, no. 5, pp. 550-557, Sep. 1987, doi: 10.1109/TGRS.1987.289833.

[32] Y. Oh, "Quantitative retrieval of soil moisture content and surface roughness from multipolarized radar observations of bare soil surfaces", in IEEE Transactions on Geoscience and Remote Sensing, vol. 42, no. 3, pp. 596-601, Mar. 2004, doi: 10.1109/TGRS.2003.821065.

[33] L. Liu, Y. Shao, K. Li, Z. Yang, "Modeling the scattering behavior of rice ears", IEEE Geoscience and Remote Sensing Letters, vol. 14, no. 4, pp. 579-583, Apr. 2017, doi: 10.1109/LGRS.2017.2665525.

[34] A. Saltelli, P. Annoni, I. Azzini, F. Campolongo, M. Ratto, and S. Tarantola, "Variance based sensitivity analysis of model output. Design and estimator for the total sensitivity index", Computer Physics Communications, vol. 181, n. 2, pp. 259-270, Feb. 2010, doi: 10.1016/j.cpc.2009.09.018.

[35] M. Sobol', "Global sensitivity indices for nonlinear mathematical models and their Monte Carlo estimates", Mathematics and Computers in Simulation, vol. 55, n. 1, pp. 271-280, Feb. 2001, doi: 10.1016/S0378-4754(00)00270-6.

[36] A. Saltelli and S. Tarantola, "On the relative importance of input factors in mathematical models", Journal of the American Statistical Association, vol. 97, n. 459, pp. 702-709, Sep. 2002, doi: 10.1198/016214502388618447.

[37] B. Iooss and C. Prieur, "Shapley effects for sensitivity analysis with correlated inputs: comparisons with Sobol' indices, numerical estimation and applications", International Journal for Uncertainty Quantification, vol. 9, n. 5, 2019, doi: 10.1615/Int.J.UncertaintyQuantification.2019028372.

[38] B. Owen, "Sobol' indices and Shapley value", SIAM/ASA J. Uncertainty Quantification, vol. 2, n. 1, pp. 245-251, Jan. 2014, doi: $10.1137 / 130936233$.

[39] L. Shapley, "A value for n-persons game”, in: H. Kuhn, A. Tucker (Eds.), Contributions to the theory of games II, Annals of mathematic studies, Princeton University Press, Princeton, NJ, 1953.

[40] R package sensitivity v 1.16.2, built under R v.4.0.2 (R Core Team, 2019). Accessed: May 5, 2021 [Online]. https://cran.rproject.org/web/packages/sensitivity/index.html

[41] C. Wang, J. Wu, Y. Zhang, G. Pan, J. Qi, and W. A. Salas, "Characterizing L-band scattering of paddy rice in southeast China with radiative transfer model and multitemporal ALOS/PALSAR imagery”, in IEEE Transactions on Geoscience and Remote Sensing, vol. 47, n. 4, pp. 988-998. Apr. 2009, doi: 10.1109/TGRS.2008.2008309.

[42] Y. Inoue et al., "Season-long daily measurements of multifrequency (Ka, Ku, X, C, and L) and full-polarization backscatter signatures over paddy rice field and their relationship with biological variables", Remote Sensing of Environment, vol. 81, n. 2, pp. 194-204, Ago. 2002, doi: 10.1016/S0034-4257(01)00343-1. 
[43] J. M. Lopez-Sanchez, J. D. Ballester-Berman, and J. Fortuny-Guasch, "Indoor wide-band polarimetric measurements on maize plants: a study of the differential extinction coefficient”, IEEE Transactions on Geoscience and Remote Sensing, vol. 44, n. 4, pp. 758-767, Apr. 2006, doi: 10.1109/TGRS.2005.862522.

[44] G. Wiseman, H. McNairn, S. Homayouni, and J. Shang, "RADARSAT-2 polarimetric SAR response to crop biomass for agricultural production monitoring”, IEEE Journal of Selected Topics in Applied Earth Observations and Remote Sensing, vol. 7, n. 11, pp. 4461-4471, Nov. 2014, doi: 10.1109/JSTARS.2014.2322311.

[45] X. Blaes, P. Defourny, U. Wegmuller, A. D. Vecchia, L. Guerriero, and P. Ferrazzoli, "C-band polarimetric indexes for maize monitoring based on a validated radiative transfer model”, IEEE Transactions on Geoscience and Remote Sensing, vol. 44, n. 4, pp. 791-800, Apr. 2006, doi: 10.1109/TGRS.2005.860969.

[46] A. Della Vecchia, P. Ferrazzoli, L. Guerriero, L. Ninivaggi, T. Strozzi, and U. Wegmuller, “Observing and modeling multifrequency scattering of maize during the whole growth cycle”, IEEE Transactions on Geoscience and Remote Sensing, vol. 46, n. 11, pp. 3709-3718, Nov. 2008, doi: 10.1109/TGRS.2008.2001885.

[47] H. Joerg, M. Pardini, I. Hajnsek, and K. P. Papathanassiou, "Sensitivity of SAR tomography to the phenological cycle of agricultural crops at X-, C-, and L-band", IEEE Journal of Selected Topics in Applied Earth Observations and Remote Sensing, vol. 11, n. 9, pp. 3014-3029, Sep. 2018, doi: 10.1109/JSTARS.2018.2845127.

[48] T. Le Toan et al., "Rice crop mapping and monitoring using ERS-1 data based on experiment and modeling results", IEEE Transactions on Geoscience and Remote Sensing, vol. 35, n. 1, pp. 41-56, Jan. 1997, doi: 10.1109/36.551933.

[49] W. Koppe et al., "Rice monitoring with multi-temporal and dual-polarimetric TerraSAR-X data", International Journal of Applied Earth Observation and Geoinformation, vol. 21, pp. 568-576, Apr. 2013, doi: 10.1016/j.jag.2012.07.016.

[50] Y. Inoue, E. Sakaiya, and C. Wang, "Potential of X-Band images from high-resolution satellite SAR sensors to assess growth and yield in paddy rice", Remote Sensing, vol. 6, n. 7, pp. 5995-6019, Jul. 2014, doi: 10.3390/rs6075995.

[51] H. Wickham, ggplot2: Elegant Graphics for Data Analysis. New York: Springer-Verlag, 2009. 